ICV: 90.90 (2018)

(c) (i) (8)

Copyright@IJCRR

\section{$\cdot \dot{\nabla}$ \\ IJCRR \\ Section: Healthcare \\ Sci. Journal Impact \\ Factor: 6.1 (2018) \\ Effectiveness of Intravenous Ketamine on Postoperative Pain Relief in Laparoscopic Appendicectomy Under Spinal Anaesthesia: A Comparative Study}

\section{Dahale Suraj ${ }^{1}$, Sireesh $\mathbf{I}^{2}$}

'Assistant Professor, Rajiv Gandhi Institute of Medical Sciences, Adilabad, India; ${ }^{2}$ MS General and Laparoscopic Surgeon, New Hope Laparoscopy center Adilabad. (Formerly Professor of Surgery, Narayana Medical College, Nellore, AP), India.

\title{
ABSTRACT
}

Introduction: Aim of our study is to assess the efficacy of intravenous ketamine to control the postoperative pain in patients who have undergone appendicectomy.

Methods: A total of 50 adult patients who were undergoing surgical intervention for acute appendicitis were examined and evaluated. They were randomly divided into two groups. In 25 cases (test group) after spinal anaesthesia and level of anaesthesia fixed at T4, $0.5 \mathrm{mg} / \mathrm{kg}$ of ketamine was given along with butorphanol, midazolam and glycopyrrolate, 10 mins before surgical incision. While in rest of 25 cases (control group), the same anaesthesia technique was used but intravenous ketamine was not given before pneumoperitoneum. The severity of pain was evaluated at 0 hrs (just after arousal), 4 hrs, $12 \mathrm{hrs}$ and $24 \mathrm{hrs}$ after surgery using 10 points visual analogue scale (VAS).

Results: The VAS score was remarkably lower in the study group as compared to the test group for all the time durations postoperatively. Also, there was no drug interaction or side effect observed in test subjects.

Conclusion: Preemptive administration of low dose ketamine has a phenomenal effect on the reduction of postoperative pain after appendicectomy.

Key Words: Appendicectomy, Low dose ketamine, Pre-emptive analgesia

\section{INTRODUCTION}

The discovery of N methyl D aspartate (NMDA) receptor and its role in the perception of pain lead to the attention of all the clinical researchers towards ketamine as a potent helper in the whole regimen of pain management ${ }^{1}$. Studies regarding the effectiveness of N-methyl-D-aspartate (NMDA) receptor antagonists for the management of post-surgical pain had been on the rise in the form of clinical trials since the last 25 to 30 years. Even after so many researches, there is a lot of debate over the advantageous effects of ketamine in the current settings. Also, ketamine comes under the group of psychotomimetic drugs and in turn, it mimics the symptoms of psychosis-like hallucinations, delusions or delirium. Due to this behaviour, its worldwide use in clinical practice is restricted. Schmid et al ${ }^{2}$ in 1999, in his study, concluded the efficacy of ketamine as an analgesic but the same study also concluded the diversity of the behaviour of ketamine in variable clinical settings. Due to such anomalous behaviour, researchers were unable to firmly calculate the risk-benefit ratio of the use of ketamine. Hence more and more studies in different clinical settings and with variable analgesic regimens are required to explore the possibility of establishment of ketamine as a safe analgesic and our study aims to address the same problems.

\section{AIM AND OBJECTIVE}

To study the effectiveness of adding intravenous ketamine before initiation of pnemoperitonium in laparoscopic appendicectomy under spinal anesthesia for management of postoperative pain.

\section{Corresponding Author:}

Dahale Suraj, Assistant Professor, Rajiv Gandhi Institute of Medical Sciences, Adilabad, India.

Email: ambad.sawan@gmail.com

ISSN: 2231-2196 (Print) ISSN: $0975-5241$ (Online)

Received: 12.06 .2020

Revised: 13.07 .2020

Accepted: 06.08 .2020

Published: 08.09.2020 


\section{MATERIALS AND METHODS}

A total number of 50 patients in the age group of 18 years to 50 years who were undergoing operative intervention of appendicectomy were taken into consideration for our study. Written, informed and voluntary consent was obtained and was grouped into two as with ketamine and control. Individuals with the history of any coronary heart disease, hypertension, history of cerebrovascular accident, epilepsy, drug abuse or any kind of psychiatric disorder were excluded from our study. In this study of a randomised control trial, the double blind technique was used. Here, the operating surgeon and the research performing doctor responsible for data analysis were unaware of the categorization of the study subjects. Spinal anaesthesia in the form of the subarachnoid block was given with 3.5 ccs of $5 \%$ bupivacaine heavy was used in all the cases. Now in 25 cases (test group), after spinal anaesthesia and level of anaesthesia fixed at T4, $25 \mathrm{mg}$ ketamine was given intravenously before the creation of pneumoperitoneum, along with $1 \mathrm{mg}$ of Butorphanol, $2 \mathrm{mg}$ of Midazolam and $0.2 \mathrm{mg}$ of Glycopyrrolate. Oxygen $5 \mathrm{~L} / \mathrm{min}$ on the venti mask was given and $\mathrm{SpO} 2$, pulse and $\mathrm{BP}$ were strictly monitored. In the rest of the 25 cases (control group), the same anaesthesia technique was used but intravenous ketamine was not given before pneumoperitoneum. After surgery, if any patient complains of pain then pethidine in the dosage of $1 \mathrm{mg} / \mathrm{kg}$ was used for anal- gesia. The severity of pain was evaluated immediately after arousal i.e $0 \mathrm{hrs}$, then $4 \mathrm{hrs}, 12 \mathrm{hrs}$ and $24 \mathrm{hrs}$ after surgical intervention. The intensity of pain was rated using the 10 points visual analogue scale (VAS) from 0 to 10 (no pain to worst pain). Patients were also checked for psychotomimetic side effects. Obtained data were tabulated in Microsoft Excel sheet and was analyzed using SPSS (statistical package for social sciences) software.

\section{RESULTS}

Overall, fifty cases were enrolled for our research out of which 25 cases were in the study (ketamine) group and 25 cases were in the control group showed in table no 1 . They were in the age group of 18 years to 50 years with consideration of all the exclusion criteria. Taking into consideration all the times after surgical intervention, the average VAS score for ketamine group was remarkably low as compared to the control group. The requirement for pethidine was also earlier in the control patients as compared to patients in whom, ketamine was used. More than $50 \%$ of patients in the ketamine group did not need postoperative analgesics. Also, it was a noteworthy finding in our study that there were no drug side-effects of ketamine. VAS: 1-3 (mild pain), 4-6 (moderate pain) and 7-10 (severe pain).

Table 1: Changes of VAS score for 24 hours after appendicectomy:

\begin{tabular}{lcccc} 
Time $($ hrs $)$ & o & 4 & 12 & 24 \\
Ketamine group & $4.1 \pm 1.0$ & $4.2 \pm 0.1$ & $2.1 \pm 1.1$ & $1.2 \pm 0.5$ \\
Control group & $6.8 \pm 1.1$ & $4.8 \pm 1.0$ & $3.7 \pm 0.9$ & $2.9 \pm 0.6$ \\
\hline
\end{tabular}

Values are in the form of mean + SD (standard deviation)

\section{DISCUSSION}

Every surgical intervention in some of the other form causes tissue impairment which in turn results in pain. In this world of rapid advances in medical research, patients require painless surgery and smooth post-surgical experience. Due to improper pain relief, the patient may land up in anxiety and psychological distress. Also, there occurs the problem of delayed mobilization. The major outcome of our study is that by using intravenous ketamine along with intravenous sedation before the creation of Pnemo-peritoneum effectively reduce the shoulder pain and discomforts due to pneumoperitoneum in patients undergoing Laparoscopic appendicectomy under spinal anaesthesia. Ketamine in high proportions intravenously acts as an anaesthetic and in on the lower side, it acts as an analgesic agent. Studies regarding ketamine are going on since last five decades ${ }^{3}$ but recently during the last decade, it has been discovered that NMDA ( $\mathrm{N}$ methyl $\mathrm{D}$ aspartate) receptor plays a vi- tal role in pain transmission and ketamine binds to these NMDA receptors as a non-selective antagonist which in turn decreases pain. ${ }^{4,5}$ Ketamine acts at both muscarinic and nicotinic receptors block Na+ channels. ${ }^{6,7,8}$ in $\mathrm{CNS}$ and interfaces with opioid receptors. It is a non-competitive inhibitor of phencyclidine receptor. ${ }^{9,10}$ In the past, there are many studies done to examine the effect of ketamine on post-surgical pain management. ${ }^{11}$ All the routes for administration of ketamine have been explored as a premedication for general anaesthesia or sedative effect. ${ }^{12,13,14}$ Also, it is noteworthy that it does not produce any side-effects or any adverse drug reaction and when given postoperatively it reduces pain by reversing central nervous sensitization. In our study, VAS measurements demonstrated the effectiveness of ketamine in controlling postoperative analgesia. Also in our study, we found out the striking difference based on statistics that, there is a higher postoperative consumption of analgesic. 


\section{CONCLUSION}

In our study, out of all the patients who received ketamine ( 25 cases), all of them were stable and no one complained of shoulder pain or any kind of discomfort. Whereas in case of the control group (25 cases), the same anaesthesia technique was used but intravenous ketamine was not given before pneumoperitoneum. Out of 25 patients in this group, 18 patients complained of shoulder pain and discomfort. So finally from our research, we concluded that using intravenous ketamine along with intravenous sedation before the creation of pneumoperitoneum effectively reduces the shoulder pain and discomforts because of pneumoperitoneum in patients undergoing Laparoscopic appendicectomy under spinal anaesthesia.

Ethical clearance- Taken from the institutional ethics committee.

Source of funding- Self.

Conflict of Interest- Nil.

\section{REFERENCES}

1. Klepstad P, Maurset A, Moberg ER, Oye I. Evidence of a role for NMDA receptors in pain perception. Eur $\mathrm{J}$ Pharmacol 1990;187:513-8.

2. Schmid R, Sandler A, Katz J. Use and efficacy of low-dose ketamine in the management of acute postoperative pain: a review of current techniques and outcomes. Pain 1999;82:111-25.
3. Jung I et al. Ketamine infusion therapy in a patient of posttraumatic syringomyelia. Korean J Pain 2008; 21: 248-51.

4. Suh J et al. Pain management via a subcutaneous infusion of ketamine in a patient with complex regional pain syndrome: a case report. Korean J Pain 2007; 20: 190-4.

5. Dickenson A, Sullivan A. Combination therapy in analgesia; seeking synergy. Curr Opin Anaesthesiol 1993; 6: 861-5.

6. Foster A, Fagg G. Neurobiology. Taking apart NMDA receptors. Nature 1987; 329: 395-6.

7. Scheller M, Bufler J, Hertle I, Schneck H, Franke C, Kochs E. Ketamine blocks currents through mammalian nicotinic acetylcholine receptor channels by interaction with both the open and the closed state. Anesth Analg 1996; 83: 830-6.

8. Hustveit O, Maurset A, Oye I. Interaction of the chiral forms of ketamine with opioid, phencyclidine, sigma and muscarinic receptors. Pharmacol Toxicol 1995; 77: 355-9.

9. Hirota K, Lambert D. Ketamine: its mechanism(s) of action and unusual clinical uses. Br J Anaesth 1996; 77: 441-4.

10. Willetts J, Balster R, Leander J. The behavioural pharmacology of NMDA receptor antagonists. Trends Pharmacol Sci 1990; 11: 423-8.

11. Yamamura T, Harada K, Okamura A, Kemmotsu O. Is the site of action of ketamine anaesthesia the N-methyl-D-aspartate receptor? Anesthesiology 1990; 72: 704-10.

12. Alderson P, Lerman J. Oral premedication for paediatric ambulatory anaesthesia: a comparison of midazolam and ketamine. Can J Anaesth 1994; 41: 221-6.

13. Cioacă R, Canavea I. Oral transmucosal ketamine: an effective premedication in children. Paediatr Anaesth 1996; 6: 361-5.

14. Weksler N, Ovadia L, Muati G, Stav A. Nasal ketamine for paediatric premedication. Can J Anaesth 1993; 40: 119-21. 